\title{
Trypanosoma cruzi load in synanthropic rodents from rural areas in Chile
}

\author{
Esteban Yefi-Quinteros ${ }^{1 \dagger}$, Catalina Muñoz-San Martín ${ }^{1 \dagger}$, Antonella Bacigalupo', Juana P. Correa ${ }^{2}$ \\ and Pedro E. Cattan ${ }^{1 *}$
}

\begin{abstract}
Background: Trypanosoma cruzi is the agent of Chagas disease, a major public health problem in Latin America. Many wild and domestic animals are naturally infected with T. cruzi; rodents are one of the groups which have been consistently detected infected in different countries. The aim of this work was to characterize blood T. cruzi load in naturally infected rodents from a Chagas disease endemic region in Chile.

Methods: Baited traps were set in domestic and peridomestic areas of rural dwellings. The rodents were anesthetized and blood sampled; DNA was extracted and the parasite load was quantified by T. cruzi satellite DNA real-time PCR assays.

Results: Seventy-one rodents of four species, Rattus rattus, Mus musculus, Phyllotis darwini and Octodon degus, were captured; $R$. rattus was the most abundant species. Fifty-nine samples (83.1\%) were T. cruzi-positive and the median value of the parasite load was 2.99 parasite equivalents (par-eq)/ml. The comparison of frequency of infection or parasite load by species showed no differences. However, one R. rattus presented very elevated parasitemia (1644 par-eq/ml).
\end{abstract}

Conclusions: The overall levels of parasitemia were similar to those found in humans in Chile. The high infection levels in exotic and endemic rodents very near to rural settlements increases their relevance as T. cruzi hosts.

Keywords: Chagas disease, Quantitative real-time PCR, Parasitemia, Host-parasite relations, Rattus rattus

\section{Background}

The protozoan parasite Trypanosoma cruzi is the causative agent of Chagas disease, a complex zoonosis transmitted by about 150 hematophagous triatomine species and supported by more than 100 species of mammals, from the southern United States to Argentina and Chile [1]. This neglected vector-borne disease is one of the most important parasitic infections in Latin America [2].

North-Central Chile $\left(17^{\circ} 50^{\prime} \mathrm{S}\right.$ to $\left.34^{\circ} 36^{\prime} \mathrm{S}\right)$ is considered a Chagas disease endemic zone, where the protozoan $T$. cruzi has four vector species $[3,4]$ and infects several endemic and exotic mammals [5].

\footnotetext{
* Correspondence: pcattan@uchile.cl

${ }^{\dagger}$ Equal contributors

'Laboratorio de Ecología, Departamento de Ciencias Biológicas Animales, Facultad de Ciencias Veterinarias y Pecuarias, Universidad de Chile, Santiago, Chile

Full list of author information is available at the end of the article
}

Rodents act as hosts of the parasite and play a role in the transmission of $T$. cruzi by connecting the sylvatic, peridomiciliary and domiciliary cycles [6], thus transporting parasites to human dwellings where they are transmitted to humans and domestic animals by triatomines [7]. The frequency of infection by $T$. cruzi in exotic and endemic rodents in Chile has been estimated previously by detecting mitochondrial kinetoplastic DNA of T. cruzi with conventional PCR assays, reaching levels of infection about $25-41 \%$ in Phyllotis darwini $[8,9], 13-70 \%$ in Octodon degus and $27 \%$ in Rattus rattus $[5,8]$ in sylvatic areas. Their relevance as hosts of $T$. cruzi in Chile has not been established previously in the peridomestic and domestic environment. In this work we evaluated the parasitic load in rodents from an endemic area for Chagas disease, discussing their role as hosts of Trypanosoma cruzi. 


\section{Methods}

\section{Collection area}

Rodents were collected from Coquimbo Region, a Chagas disease endemic zone located in the North-Central zone of Chile (Fig. 1), which is characterized by an arid Mediterranean climate. The rain is concentrated in winter, between May and August, but it has a marked water deficit during most of the year. Its geography is characterized by a series of mountain ranges and transverse valleys with rivers. The north-facing slopes are particularly exposed, and have low vegetation cover; on the south-facing exposure slopes thick grasses and shrubs are frequent. The valleys, on the other hand, have fertile soils [10]. The studied localities have an altitude range between 300-1800 $\mathrm{m}$ above sea level (Fig. 2).

\section{Trapping procedures}

Domestic (inside dwellings) and peridomestic (areas around the house with permanent or transitory structures within the property limits) areas of rural dwellings were prospected using Tomahawk ${ }^{\mathrm{TM}}$ (WI, USA), Sherman ${ }^{\text {тм }}$ (FL, USA) and Rodentrap ${ }^{\text {тм }}$ traps (Santiago, Chile) baited with rolled oats, and provided with cotton bedding. Trapping was conducted from December 2014 through February 2015 and in January 2016, corresponding to the austral summer. The total number of traps set in each dwelling, including domestic or peridomestic areas ranged between 12 and 16. They were placed according to the availability of sites with shadow outside the house, and the permission of the owners to place traps inside; within the dwelling, the maximum traps set were 6 . The traps were activated for 3 nights with a total capture effort of 3315 trap-nights. The number of traps set in domestic or peridomestic areas per locality is detailed in Additional file 1: Table S1. Prospected peridomestic areas were sites near each house, adjacent, within or underneath firewood, shrubs, animal corrals, chicken coops, rock piles, construction materials, warehouses and food or waste accumulations. Inside dwellings,

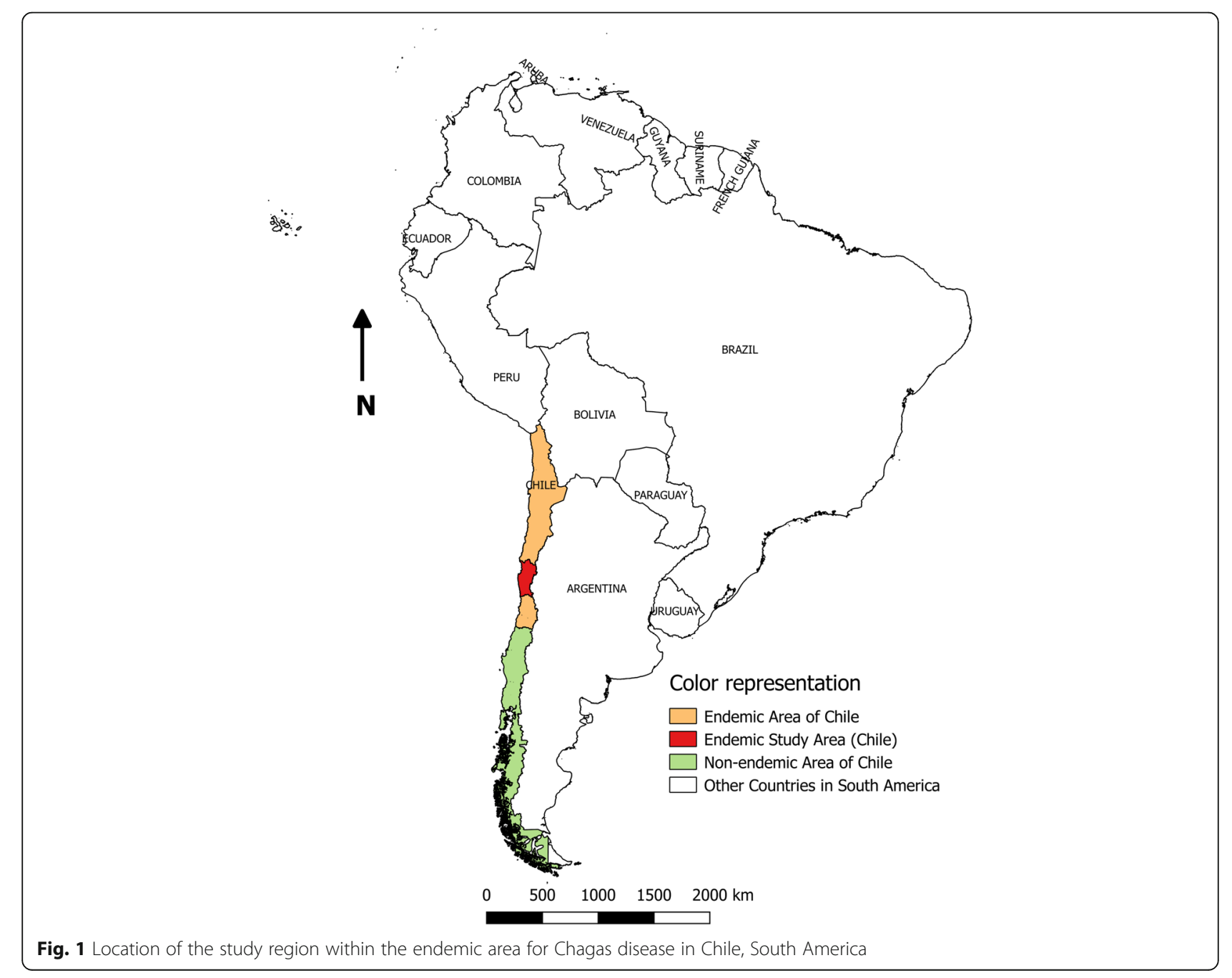




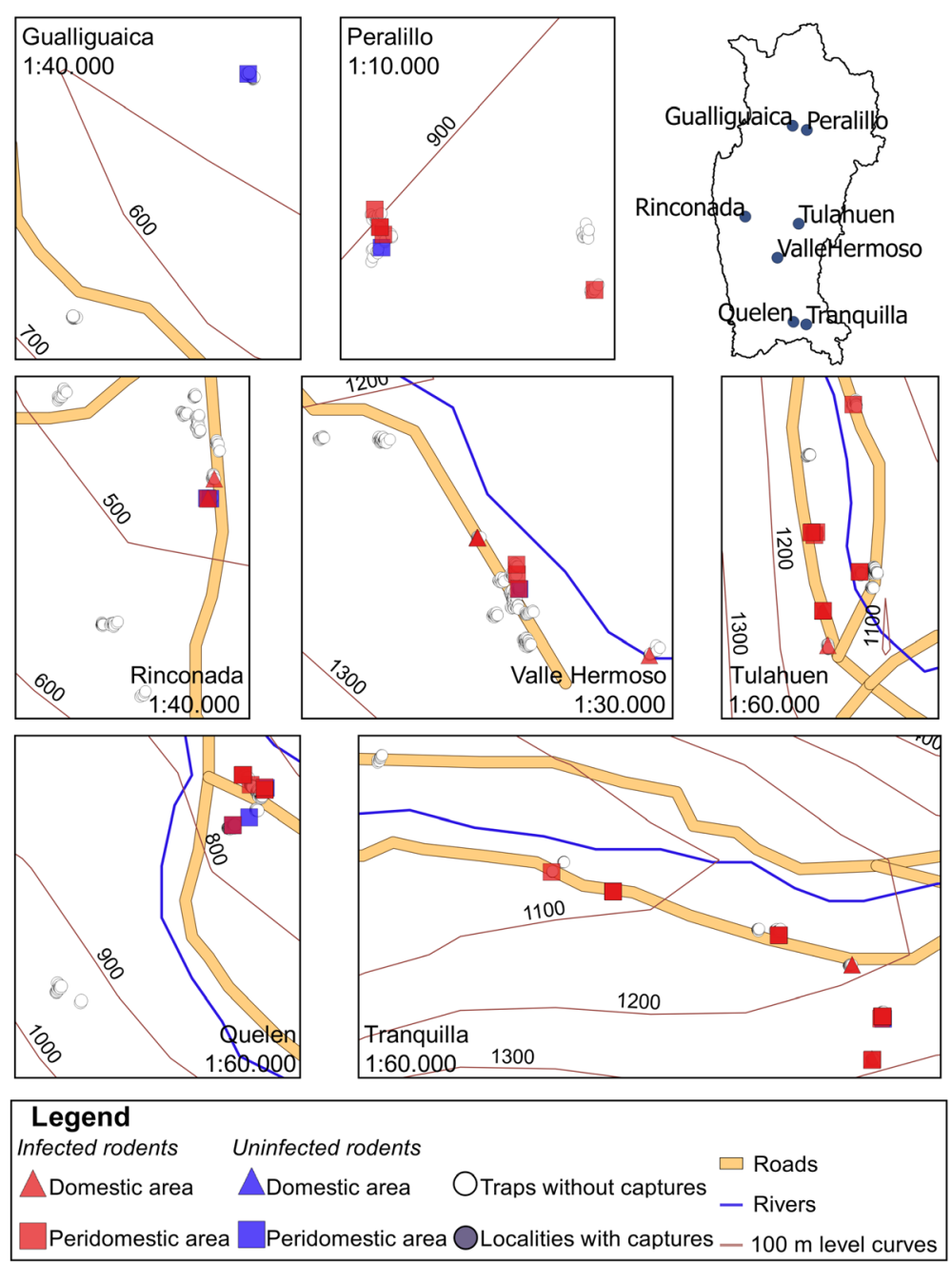

Fig. 2 Location of the rodents by trapping area and infection status in each studied locality, within the study region

traps were set in bedrooms, kitchens, bathrooms, dining rooms and attics.

\section{Biological samples}

Peripheral blood samples of 71 rodents were incorporated in the study. They were examined and anesthetized according to species: the exotic rodents (Rattus rattus and Mus musculus) were anesthetized with isoflurane, and endemic rodents (Phyllotis darwini and Octodon degus), with isoflurane induction, and intramuscular Ketamine-Xylazine anesthesia $(40-85 \mathrm{mg} / \mathrm{kg}+5-21$ $\mathrm{mg} / \mathrm{kg}$ ). All the specimens were weighed, measured (total body length and tail length) and their sex was determined. Blood samples were obtained by puncture of the saphenous vein $(O$. degus), masseteric vein $(P$. darwini) or cardiac puncture ( $R$. rattus and $M$. musculus). A minimum of $0.2 \mathrm{ml}$ of blood sample was obtained from each rodent and immediately preserved with an equal volume of $6 \mathrm{~mol} / \mathrm{l}$ guanidine- $\mathrm{HCl}-0.2 \mathrm{~mol} / \mathrm{l}$ EDTA solution (GEB samples). After sampling, endemic rodents were ear-tagged and released at the point of capture or in the vicinity, if they were captured indoors, and exotic rodents were euthanized by anesthesia overdose. The samples were stored in the laboratory at $4{ }^{\circ} \mathrm{C}$ until DNA extraction.

\section{DNA extraction}

DNA extraction from $200 \mu \mathrm{l}$ of GEB samples was performed using the UltraCleanTM BloodSpin ${ }^{\mathrm{Tm}}$ Kit (MO $\mathrm{BIO}, \mathrm{CA}, \mathrm{USA}$ ) according to the manufacturer's instructions, with $100 \mu \mathrm{l}$ of solution B5 in the elution step. Total DNA concentration from biological samples was quantified to assess the amount and integrity of genomic DNA [11, 12] using Qubit dsDNA HS Assay Kit (Life Technologies, OR, USA) according to the manufacturer's instructions. The eluted samples were stored at $-20{ }^{\circ} \mathrm{C}$ until qPCR assays. 


\section{Trypanosoma cruzi satellite DNA real-time PCR assays} The parasite load was quantified in each sample by qPCR assays using T. cruzi nuclear satellite DNA primers Cruzi 1 and Cruzi 2 [13]. Assays were performed in a Rotor-Gene ${ }^{\circ} \mathrm{Q}$ (Qiagen, CA, USA), with a final volume of $20 \mu \mathrm{l}$ containing $2 \mu \mathrm{l}$ DNA template, $5 \times$ HOT FIREPol ${ }^{\circ}$ EvaGreen $^{\circ}$ qPCR Mix Plus (Solis BioDyne, Tartu, Estonia), $0.3 \mu \mathrm{M}$ of each primer and nuclease free water. The cycling conditions were: a preincubation for $15 \mathrm{~min}$ at $95{ }^{\circ} \mathrm{C}$, followed by 40 cycles at $95{ }^{\circ} \mathrm{C}$ for $15 \mathrm{~s}, 65^{\circ} \mathrm{C}$ for $20 \mathrm{~s}$ and $72{ }^{\circ} \mathrm{C}$ for $20 \mathrm{~s}$. After all amplification cycles, a melting curve was run. Each sample was tested in duplicate.

Considering that one parasite cell harbors approximately $200 \mathrm{fg}$ of DNA [14, 15], the standard curve for absolute quantification was performed with a 10-fold serial dilution of the DNA extracted from a T. cruzi free $R$. rattus GEB sample spiked with $10^{6}$ parasite equivalents $/ \mathrm{ml}$ (par-eq/ml) [16], so the standard was submitted to an equivalent loss of genomic DNA due to the extraction process as the samples. Given the variability in the number of copies of the nuclear satellite DNA previously described [14, 16, 17], the curve was made with equal quantities (20 ng each/200 $\mu \mathrm{l}$ blood) of the clonal reference strains Dm28c (TcId) and Y (TcII) to reduce the differences in the detection limits; one strain from the group with the highest number of copies (TcII) and one strain of the group with the lowest number of copies (TcI) were mixed [18-20].

\section{Statistical methods}

The body mass index (BMI) of each rodent was calculated as $\mathrm{BMI}=$ mass $/(\text { total length }- \text { tail length })^{2}$ [5], and was tested for normality and homogeneity of variance. We analysed the frequency of infection by species and by sex, with the Fisher's exact test (Statacorp. 2005. Stata Statistical Software: Release 9.1. College Station, TX, USA: Statacorp LLC.), and we tested if the BMI was different according to infection status with the unpaired Student's t-test. The parasite load was evaluated by species using the Kruskal-Wallis H-test, and by sex, with the Mann Whitney U-test. The BMI and T. cruzi load correlation was evaluated by the Spearman's test (GraphPad Prism version 7.00 for Windows, GraphPad Software, La Jolla CA, USA, https://www.graphpad.com/). All the tests were performed with a significance level of $\alpha=0.05$.

\section{Results \\ Trapping}

Seventy-one rodents were captured in domestic or peridomestic areas: $55 R$. rattus, six $M$. musculus, six $P$. darwini and four $O$. degus (Table 1). The location of the captured rodents and their infection status are shown in Fig. 2. In two localities there were no rodents captured (Cochiguaz and Matancilla, localities not shown in Fig. 2). The captured rodents were 28 females and 43 males, with a mean BMI of $0.29 \mathrm{~g} / \mathrm{cm}^{2}(\mathrm{SD} \pm 0.08)$.

\section{DNA concentration}

Genomic DNA was detected in all extracted samples, and their concentration values ranged between 0.11$28.2 \mathrm{ng} / \mu \mathrm{l}$ (mean 3.16, $\mathrm{SD} \pm 4.84$ ).

\section{Trypanosoma cruzi satellite DNA quantitative real-time PCR assays}

All captured rodents $(n=71)$ were evaluated using qPCR assays. Overall 59 rodent samples (83.1\% of captures) were positive to T. cruzi: 46 R. rattus (83.6\% of the captures of this species), 5 M. musculus (83.3\%), 6 P. darwini (100\%) and 2 O. degus (50\%) (Table 1). According to sex, 25 (89.3\%) females and $34(79.1 \%)$ males were infected. The status of $T$. cruzi infection did not show significant differences by species (Fisher's exact test: $P=0.225$ ) or by sex (Fisher's exact test: $P=0.341$ ). Normality (Shapiro-Wilk: infected $W=0.98, P=0.377$; uninfected $W=0.98, P=$ $0.955)$ and homogeneity of variance (Levene test: $w 0=$ 1.97; $\left.d f_{(1,63)} ; P=0.165\right)$ of the BMI according to infection status were not rejected. BMI of infected (mean $0.29 \mathrm{~g} /$ $\mathrm{cm}^{2}, \mathrm{SD} \pm 0.08$ ) and uninfected (mean $0.32 \mathrm{~g} / \mathrm{cm}^{2}, \mathrm{SD} \pm$ $0.10)$ did not show significant differences (unpaired t-test: $\left.t_{(63)}=1.41, P=0.121\right)$.

In the quantification, the threshold cycle $(\mathrm{Ct})$ values ranged between 25.68-36.45 (mean 30.76, SD \pm 1.93). Parasite loads in the 59 positive samples were calculated using the standard curve of GEB sample spiked with a mixture of strains (efficiency $=0.98, R^{2}=0.993$ ), and

Table 1 Description of the rodents captured in rural dwellings of Coquimbo Region, Chile.

\begin{tabular}{|c|c|c|c|c|c|c|c|c|}
\hline \multirow[t]{2}{*}{ Species } & \multicolumn{2}{|c|}{ Sex } & \multicolumn{2}{|c|}{ Trapping area $n$ (\%) } & \multicolumn{2}{|c|}{ Infection status n (\%) } & \multirow{2}{*}{$\begin{array}{l}\text { BMI } \\
\text { Mean } \pm \text { SD }\left(\mathrm{g} / \mathrm{cm}^{2}\right)\end{array}$} & \multirow{2}{*}{$\begin{array}{l}\text { Median parasite load (range) } \\
\text { (par-eq/ml) }\end{array}$} \\
\hline & $\mathrm{F}$ & M & Domestic & Peridomestic & Infected & Uninfected & & \\
\hline Rattus rattus & 22 & 33 & $10(18.2)$ & $45(91.8)$ & $46(83.6)$ & $9(16.4)$ & $0.29 \pm 0.07$ & $3.27(0.07-1644.34)$ \\
\hline Mus musculus & 2 & 4 & $0(0.0)$ & $6(100)$ & $5(83.3)$ & $1(16.4)$ & $0.19 \pm 0.02$ & 2.45 (1.67-8.52] \\
\hline Phyllotis darwini & 2 & 4 & $2(33.3)$ & $4(66.7)$ & $6(100)$ & $0(0)$ & $0.30 \pm 0.05$ & 3.37 (2.21-6.89) \\
\hline Octodon degus & 2 & 2 & $1(25.0)$ & $3(75.0)$ & $2(50.0)$ & $2(50.0)$ & $0.40 \pm 0.04$ & $3.40(1.64-5.15)$ \\
\hline Total & 28 & 43 & $13(18.3)$ & $58(81.7)$ & 59 (83.1) & $12(16.9)$ & $0.29 \pm 0.08$ & $3.23(0.07-1644.34)$ \\
\hline
\end{tabular}

Abbreviations: $F$ female, $M$ male 
fluctuated between $<1$ and $109 \mathrm{par}-\mathrm{eq} / \mathrm{ml}$ with a median value of 2.99 par-eq $/ \mathrm{ml}$ (Fig. 3). An interesting finding was one outlier ( $R$. rattus) with a high parasite load (1644 par-eq $/ \mathrm{ml})$. The parasite loads did not show significant differences when evaluating by species (KruskalWallis H-test: $\chi^{2}=0.208, d f=3, P=0.976$ ) or by sex (Mann-Whitney U-test: $U=417.5, Z=-0.12, P=0.912$ ). No correlation between the body mass index and the parasite load was obtained (Spearman's $r=-0.27, P=$ 0.059). Results by individual are included in Additional file 2: Table S2.

\section{Discussion}

The main way of transmission of $T$. cruzi in rodents from Chile is supposed to be vectorial, and Mepraia spinolai is the most important vector in the wild, reaching infection levels up to $76 \%$ [21]. Hence, this is likely to be the main way T. cruzi-infected rodents became infected. Also, the oral route is probably a frequent form of circulation of the parasite in the wild cycle by carnivorous, insectivorous and licking behavior [22]. The protozoan infection of rodents did not differ between sexes, which agrees with a previous report [5]; however, female rodents of the most abundant species ( $R$. rattus) might have a greater effect on the long-term transmission of $T$. cruzi by means of their high reproductive ratio, conjugated with the possible propagation of the agent to their offspring, as was described for Rattus norvegicus in experimental infections [23], maintaining the parasite in time.

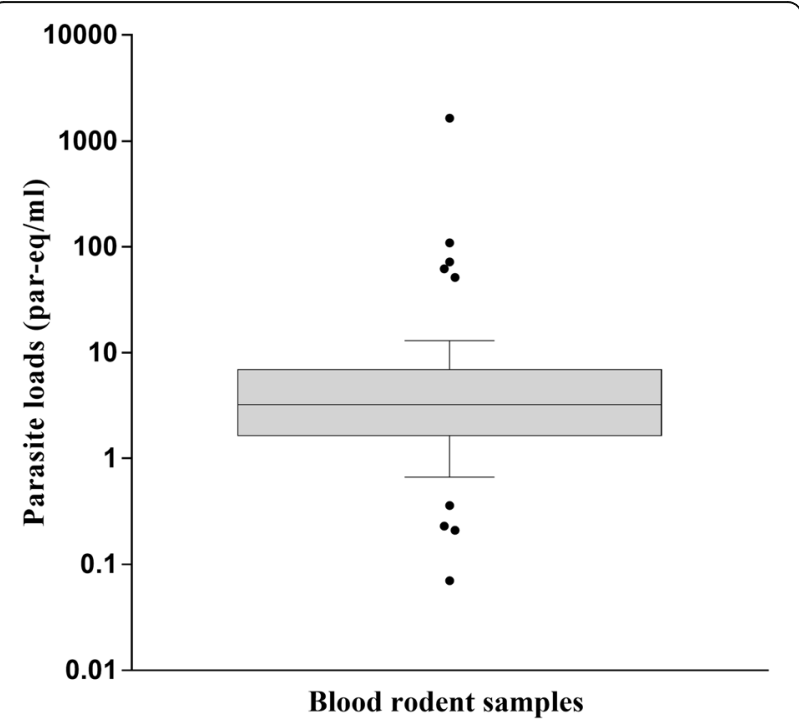

Fig. 3 Trypanosoma cruzi loads in rodent blood samples. Parasite loads are represented in logaritmic scale as parasite equivalents $/ \mathrm{ml}$. The line inside the box plot represents the median, and the box extends from lower to upper quartiles. Whiskers indicate the 90th and 10th percentiles and dots represent the outliers
Rodents are frequently found in triatomines' blood meals [24, 25]. If the rodent species sampled in our study are a food source for triatomines, their high infection levels with $T$. cruzi may be indicating that wild or peridomestic triatomines are getting these parasites through their blood meals, and in this way they are favoring the transmission of $T$. cruzi in the wild and peridomestic cycles. The existence of animal food sources in the peridomicile or even inside dwellings has the possible consequence of permitting the establishment and maintenance of vector colonies in these areas. Particularly, this study shows that $R$. rattus is a relevant host in domestic and peridomestic cycles in Chagas disease endemic zones, because of its high frequency of infection and its higher population abundances [26]. However, we also found the presence of the endemic species $O$. degus and $P$. darwini, usually classified as wild, being very close to dwellings, breaking the theoretical limits of the wild and domestic cycles.

The quantification of T. cruzi in rodents' blood revealed that their levels of parasitemia were similar to those found in O. degus from sylvatic areas (median value: 6.2 par-eq/ ml) [27] and humans. The median value in Chilean human samples (6.42 par-eq/ml) [19], and the median values found in Colombian and Argentinian human samples (2.3 and 1.9 par-eq/ml, respectively) [16] is not far from that detected in this study, of $2.99 \mathrm{par}-\mathrm{eq} / \mathrm{ml}$. Interestingly, there were four rodents with parasite loads ranging between 51-109 par-eq/ml, which are similar to the loads reported for chronic Chagas cardiomyopathy patients [16]. The outlier load (1644 par-eq/ml) approaches the loads found in HIV/T. cruzi co-infection patients with Chagas disease reactivation (median value: 1428 parasites/ ml) [28] and in acute congenital Chagas in newborns (> 1000 parasites/ml) [29]. Trypanosoma cruzi load in rodents' blood is not related to species, sex or BMI, so it is probable that the immune response regulates the parasite load in these species [30]. It can also be related to the parasite load inoculated when the rodents got infected [31], which was not evaluated here.

We showed that rodents are relevant hosts for $T$. cruzi in domestic and peridomestic locations of Chagas disease endemic areas, without discarding that other mammals may be playing a role in the parasite's cycle. We propose that the maintenance of T. cruzi in North-Central Chile is ensured by the abundance of different native and exotic rodent species and their high levels of infection $[8,26,32]$. In fact, rodents may be used as sentinels, as their chronic infections [5] allow detection of exposure to the pathogen in an extended temporal manner, reflecting the risk of infection in local areas. Furthermore, the simple way that they can be captured and sampled facilitates their use to detect $T$. cruzi. In particular, exotic species such as $M$. musculus and $R$. rattus relate closely with human activities 
[33], and those species could be removed from these areas by trapping procedures, given that they are considered plagues because of their risk of transmitting several pathogens [34]. The removal of rodents from within and around dwellings in other settings has reduced the risk of having vector colonies, thus diminishing the risk of human vectorial transmission of T. cruzi [35]. In this context, rodent control of exotic species in areas occupied by people is highly recommended.

\section{Conclusions}

Our study confirmed that $T$. cruzi circulates very near to rural human population in the studied area, with rodents acting as relevant hosts for the parasite in domestic and peridomestic locations. In fact, $83.1 \%$ of rodents were infected with parasite loads similar to those in human cases. Rodent control of exotic species should be encouraged, along with vector control, given that triatomines will probably be infected as well.

\section{Additional files}

Additional file 1: Table S1. Number of traps set per locality, by trapping area. (DOCX $16 \mathrm{~kb}$ )

Additional file 2: Table S2. Results per individual. (XLSX 14 kb)

\section{Abbreviations}

DNA: Deoxyribonucleic acid; PCR: Polymerase chain reaction; par-eq/ml: Parasite equivalents per millilitre; EDTA: Ethylenediaminetetraacetic acid; GEB: Guanidine hydrochloride EDTA blood; dsDNA: Double-stranded DNA; qPCR: Quantitative real-time PCR; BMI: Body mass index; SD: Standard deviation; Ct: Cycle threshold; HIV: Human immunodeficiency virus

\section{Acknowledgments}

We are very grateful to Ministry of Health, Chile (MINSAL) and SEREMI de Salud Coquimbo, Anita Bonell and Alejandro García for field support; to María Fernanda González, Solange Urrutia, and all the students that participated in the fieldwork.

\section{Funding}

CONICYT FONDECYT grant numbers 1140650 (EY-Q, AB, JPC and PEC) 3170799 (CM-SM), and 1170367 (JPC). The funding agency had no role in the design of the study and collection, analysis, interpretation of data and in writing the manuscript.

\section{Availability of data and materials}

All data generated or analysed during this study are included in this published article and in Additional files 1, 2.

\section{Authors' contributions}

PEC designed the study, interpreted the results, and critically revised the manuscript. EY-Q and AB obtained the samples. CM-SM standardized the molecular technique. EY-Q and CM-SM performed the molecular analyses. $C M-S M$ and $A B$ performed statistical analyses and interpreted the results. EY$\mathrm{Q}, \mathrm{CM}-\mathrm{SM}, \mathrm{AB}$, JPC and PEC wrote the manuscript. All authors read and approved the final manuscript

\section{Ethics approval and consent to participate}

The Bioethics Committee of the Faculty of Veterinary Sciences of the University of Chile approved the study, and the Chilean Agriculture and Livestock Bureau approved trapping procedures by the SAG Exempt Resolution Number 7637/2014. All homeowners agreed to participate in the study, allowing micromammal captures in and around their dwellings with a written informed consent.

\section{Consent for publication}

Not applicable.

\section{Competing interests}

The authors declare that they have no competing interests.

\section{Publisher's Note}

Springer Nature remains neutral with regard to jurisdictional claims in published maps and institutional affiliations.

\section{Author details}

${ }^{1}$ Laboratorio de Ecología, Departamento de Ciencias Biológicas Animales, Facultad de Ciencias Veterinarias y Pecuarias, Universidad de Chile, Santiago, Chile. ${ }^{2}$ Laboratorio de Ecología Evolutiva, Departamento de Ciencias Ecológicas, Facultad de Ciencias, Universidad de Chile, Santiago, Chile.

Received: 3 November 2017 Accepted: 5 March 2018

Published online: 12 March 2018

\section{References}

1. Coura JR. Chagas disease: control, elimination and eradication. Is it possible? Mem Inst Oswaldo Cruz. 2013;108:962-7.

2. Miles MA, Llewellyn MS, Lewis MD, Yeo M, Baleela R, Fitzpatrick S, et al. The molecular epidemiology and phylogeography of Trypanosoma cruzi and parallel research on Leishmania: looking back and to the future. Parasitology. 2009;136:1509-28.

3. Bacigalupo A, Torres-Perez F, Segovia V, García A, Correa JP, Moreno L, et al. Sylvatic foci of the Chagas disease vector Triatoma infestans in Chile: description of a new focus and challenges for control programs. Mem Inst Oswaldo Cruz. 2010;105:633-41.

4. Frias-Lasserre D. A new species and karyotype variation in the bordering distribution of Mepraia spinolai (Porter) and Mepraia gajardoi Frias et al. (Hemiptera: Reduviidae: Triatominae) in Chile and its parapatric model of speciation. Neotrop Entomol. 2010:39:572-83.

5. Botto-Mahan C, Bacigalupo A, Correa JP, Oda E, Solari A. Field assessment of Trypanosoma cruzi infection and host survival in the native rodent Octodon degus. Acta Trop. 2012;122:164-7.

6. Pinto CM, Ocana-Mayorga S, Lascano MS, Grijalva MJ. Infection by trypanosomes in marsupials and rodents associated with human dwellings in Ecuador. J Parasitol. 2006;92:1251-5.

7. Ramsey JM, Gutierrez-Cabrera AE, Salgado-Ramirez L, Peterson AT, SanchezCordero V, Ibarra-Cerdena CN. Ecological connectivity of Trypanosoma cruzi reservoirs and Triatoma pallidipennis hosts in an anthropogenic landscape with endemic Chagas disease. PloS One. 2012;7:e46013.

8. Galuppo S, Bacigalupo A, Garcia A, Ortiz S, Coronado X, Cattan PE, Solari A. Predominance of Trypanosoma cruzi genotypes in two reservoirs infected by sylvatic Triatoma infestans of an endemic area of Chile. Acta Trop. 2009; 111:90-3.

9. Rozas M, Botto-Mahan C, Coronado X, Ortiz S, Cattan PE, Solari A. Short report: Trypanosoma cruzi infection in wild mammals from a chagasic area of Chile. Am J Trop Med Hyg. 2005;73:517-9.

10. Schofield CJ, Apt W, Miles MA. The ecology of Chagas disease in Chile. Ecol Dis. 1982;1:117-29.

11. Brisco MJ, Latham S, Bartley PA, Morley AA. Incorporation of measurement of DNA integrity into qPCR assays. Biotechniques. 2010;49:893-7.

12. Sedlackova T, Repiska G, Celec P, Szemes T, Minarik G. Fragmentation of DNA affects the accuracy of the DNA quantitation by the commonly used methods. Biol Proced Online. 2013:15:5.

13. Piron M, Fisa R, Casamitjana N, López-Chejade P, Puig L, Vergés M, et al. Development of a real-time PCR assay for Trypanosoma cruzi detection in blood samples. Acta Trop. 2007:103:195-200.

14. Duffy T, Bisio M, Altcheh J, Burgos JM, Diez M, Levin MJ, et al. Accurate realtime PCR strategy for monitoring bloodstream parasitic loads in Chagas disease patients. PLoS Negl Trop Dis. 2009;3:e419.

15. Kooy RF, Ashall F, Van der Ploeg M, Overdulve JP. On the DNA content of Trypanosoma cruzi. Mol Biochem Parasitol. 1989;36:73-6.

16. Moreira OC, Ramirez JD, Velazquez E, Melo MF, Lima-Ferreira C, Guhl F, et al. Towards the establishment of a consensus real-time qPCR to monitor 
Trypanosoma cruzi parasitemia in patients with chronic Chagas disease cardiomyopathy: a substudy from the BENEFIT trial. Acta Trop. 2013;125:23-31.

17. lenne S, Pedroso A, Carmona EFR, Briones MR, Zingales B. Network genealogy of 195-bp satellite DNA supports the superimposed hybridization hypothesis of Trypanosoma cruzi evolutionary pattern. Infect Genet Evol. 2010;10:601-6.

18. Ramirez JC, Cura Cl, da Cruz Moreira O, Lages-Silva E, Juiz N, Velazquez E, et al. Analytical validation of quantitative real-time PCR methods for quantification of Trypanosoma cruzi DNA in blood samples from Chagas disease patients. J Mol Diagn. 2015;17:605-15.

19. Muñoz-San Martín C, Apt W, Zulantay I. Real-time PCR strategy for the identification of Trypanosoma cruzi discrete typing units directly in chronically infected human blood. Infect Genet Evol. 2017;49:300-8.

20. Duffy T, Cura Cl, Ramirez JC, Abate T, Cayo NM, Parrado R, et al. Analytical performance of a multiplex real-time PCR assay using TagMan probes for quantification of Trypanosoma cruzi satellite DNA in blood samples. PLoS Negl Trop Dis. 2013;7:e2000.

21. Coronado X, Rozas M, Botto-Mahan C, Ortiz S, Cattan PE, Solari A. Molecular epidemiology of Chagas disease in the wild transmission cycle: the evaluation in the sylvatic vector Mepraia spinolai from an endemic area of Chile. Am J Trop Med Hyg. 2009;81:656-9.

22. Roque AL, Xavier SC, da Rocha MG, Duarte AC, D'Andrea PS, Jansen AM. Trypanosoma cruzi transmission cycle among wild and domestic mammals in three areas of orally transmitted Chagas disease outbreaks. Am J Trop Med Hyg. 2008;79:742-9.

23. Moreno EA, Ramírez AM, Alarcón ME, Lugo de Yarbuh A, Villarreal J, Araujo $\mathrm{S}$, et al. Transmisión congénita de Trypanosoma cruzi en ratas Wistar de segunda generación. Bol Malariol Salud Amb. 2010;50:29-38.

24. Chacon F, Bacigalupo A, Quiroga JF, Ferreira A, Cattan PE, Ramirez-Toloza G. Feeding profile of Mepraia spinolai, a sylvatic vector of Chagas disease in Chile. Acta Trop. 2016;162:171-3.

25. Buitrago R, Bosseno MF, Depickère S, Waleckx E, Salas R, Aliaga C, et al. Blood meal sources of wild and domestic Triatoma infestans (Hemiptera: Reduviidae) in Bolivia: connectivity between cycles of transmission of Trypanosoma cruzi. Parasit Vectors. 2016;9:214

26. Lobos G, Ferres M, Palma RE. Presencia de los géneros invasores Mus y Rattus en áreas naturales de Chile: un riesgo ambiental y epidemiológico. Rev Chil Hist Nat. 2005;78:113-24.

27. Rojo G, Sandoval-Rodriguez A, Lopez A, Ortiz S, Correa JP, Saavedra M, et al. Within-host temporal fluctuations of Trypanosoma cruzi discrete typing units: the case of the wild reservoir rodent Octodon degus. Parasit Vectors. 2017;10:380.

28. de Freitas VLT, da Silva SCV, Sartori AM, Bezerra RC, Westphalen EVN, Molina TD, et al. Real-time PCR in HIV/Trypanosoma cruzi coinfection with and without Chagas disease reactivation: association with HIV viral load and CD4 level. PLoS Negl Trop Dis. 2011:5:e1277.

29. Virreira M, Truyens C, Alonso-Vega C, Brutus L, Jijena J, Torrico F, et al. Comparison of Trypanosoma cruzi lineages and levels of parasitic DNA in infected mothers and their newborns. Am J Trop Med Hyg. 2007;77:102-6.

30. Cardillo F, de Pinho RT, Antas PR, Mengel J. Immunity and immune modulation in Trypanosoma cruzi infection. Pathog Dis. 2015;73:ftv082.

31. Borges DC, Araujo NM, Cardoso CR, Lazo Chica JE. Different parasite inocula determine the modulation of the immune response and outcome of experimental Trypanosoma cruzi infection. Immunology. 2013;138:145-56.

32. Oda E, Solari A, Botto-Mahan C. Effects of mammal host diversity and density on the infection level of Trypanosoma cruzi in sylvatic kissing bugs. Med Vet Entomol. 2014;28:384-90.

33. Muñoz-Zanzi C, Mason M, Encina C, Gonzalez M, Berg S. Household characteristics associated with rodent presence and Leptospira infection in rural and urban communities from southern Chile. Am J Trop Med Hyg. 2014:90:497-506.

34. Himsworth CG, Parsons KL, Jardine C, Patrick DM. Rats, cities, people, and pathogens: a systematic review and narrative synthesis of literature regarding the ecology of rat-associated zoonoses in urban centers. Vector Borne Zoonotic Dis. 2013;13:349-59.

35. De Urioste-Stone SM, Pennington PM, Pellecer E, Aguilar TM, Samayoa G, Perdomo HD, et al. Development of a community-based intervention for the control of Chagas disease based on peridomestic animal management: an eco-bio-social perspective. Trans R Soc Trop Med Hyg. 2015;109:159-67.

\section{Submit your next manuscript to BioMed Central and we will help you at every step:}

- We accept pre-submission inquiries

- Our selector tool helps you to find the most relevant journal

- We provide round the clock customer support

- Convenient online submission

- Thorough peer review

- Inclusion in PubMed and all major indexing services

- Maximum visibility for your research

Submit your manuscript at www.biomedcentral.com/submit
) Biomed Central 